OPEN ACCESS

Edited by: Nicola Maggio, Sheba Medical Center, Israel

Reviewed by: Christiane Charriaut-Marlangue, Institut National de la Santé et de la

Recherche Médicale (INSERM),

France

Aniko Korosi,

University of Amsterdam, Netherlands

*Correspondence:

Diederik van de Beek d.vandebeek@amc.uva.nl

Received: 17 January 2018 Accepted: 05 April 2018 Published: 24 April 2018

Citation:

Hoogland ICM, Westhoff $D$, Engelen-Lee J-Y, Melief J, Valls Serón M, Houben-Weerts JHMP, Huitinga I, van Westerloo DJ, van der Poll T, van Gool WA and van de Beek D (2018) Microglial Activation After Systemic Stimulation With Lipopolysaccharide and Escherichia coli. Front. Cell. Neurosci. 12:110. doi: $10.3389 /$ fncel.2018.00110

\section{Microglial Activation After Systemic Stimulation With Lipopolysaccharide and Escherichia coli}

\author{
Inge C. M. Hoogland ${ }^{1}$, Dunja Westhoff ${ }^{1}$, Joo-Yeon Engelen-Lee ${ }^{1}$, Jeroen Melief ${ }^{2}$, \\ Mercedes Valls Serón ${ }^{1}$, Judith H. M. P. Houben-Weerts ${ }^{1}$, Inge Huitinga ${ }^{2}$, \\ David J. van Westerloo ${ }^{3}$, Tom van der Poll ${ }^{4}$, Willem A. van Gool ${ }^{1}$ and \\ Diederik van de Beek ${ }^{1 *}$
}

${ }^{1}$ Department of Neurology, Center of Infection and Immunity Amsterdam, Academic Medical Center, University of Amsterdam, Amsterdam, Netherlands, ${ }^{2}$ Netherlands Institute for Neuroscience - KNAW, Amsterdam, Netherlands, ${ }^{3}$ Intensive Care Medicine, Leiden University Medical Center, Leiden, Netherlands, ${ }^{4}$ Center of Experimental Molecular Medicine, Academic Medical Center, Amsterdam, Netherlands

Background: Microglial activation after systemic infection has been suggested to mediate sepsis-associated delirium. A systematic review of animal studies suggested distinct differences between microglial activation after systemic challenge with live bacteria and lipopolysaccharide (LPS). Here, we describe a mouse model of microglial activation after systemic challenge with live Escherichia coli (E. coli) and compare results with systemic challenge with LPS.

Methods: Sixty mice were intraperitoneally injected with E. coli $\left(1 \times 10^{4}\right.$ colony-forming units) and sacrificed at 12, 20, 48, and $72 \mathrm{~h}$ after inoculation. For 48 and $72 \mathrm{~h}$ time points, mice were treated with ceftriaxone. Thirty mice were intraperitoneally injected with LPS (5 $\mathrm{mg} / \mathrm{kg}$ ) and sacrificed 3 and $48 \mathrm{~h}$ after inoculation; 48 control mice were intraperitoneally injected with isotonic saline. Microglial response was monitored by immunohistochemical staining with lba-1 antibody and flow cytometry; and inflammatory response by mRNA expression of pro- and anti-inflammatory mediators.

Results: Mice infected with live E. coli showed microglial activation $72 \mathrm{~h}$ post-inoculation, with increased cell number in cortex $(p=0.0002)$, hippocampus $(p=0.003)$, and thalamus $(p=0.0001)$, but not in the caudate nucleus/putamen ( $p=0.33$ ), as compared to controls. At $72 \mathrm{~h}$, flow cytometry of microglia from $E$. coli infected mice showed increased cell size $(p=0.03)$ and CD45 expression $(p=0.03)$, but no increase in CD11b expression, and no differences in brain mRNA expression of inflammatory mediators as compared to controls. In mice with systemic LPS stimulation, microglial cells were morphologically activated at the $48 \mathrm{~h}$ time point with increased cell numbers in cortex $(p=0.002)$, hippocampus $(p=0.0003)$, thalamus $(p=0.007)$, and caudate nucleus/putamen ( $p<0.0001$ ), as compared to controls. At $48 \mathrm{~h}$, flow cytometry of microglia from LPS stimulated mice showed increased cell size $(p=0.03)$, CD45 $(p=0.03)$, and CD11b $(p=0.04)$ expression. Brain mRNA expression of TNF- $\alpha$ $(p=0.02), I L-1 \beta(p=0.02)$, and MCP-1 $(p=0.03)$ were increased as compared to controls. 
Interpretation: Systemic challenge with live E. coli causes a neuro-inflammatory response, but this response occurs at a later time point and is less vigorous as compared to LPS stimulation. The E. coli model mimics the clinical situation of infection associated delirium more closely than stimulation with supra-natural LPS.

Keywords: microglia, microglial activation, systemic infection, lipopolysaccharide, Escherichia coli, neuroinflammation, mouse model

\section{INTRODUCTION}

A delirium is the most common complication among hospitalized older people and has been associated with detrimental long-term effects (Inouye, 2006). A meta-analysis showed that delirium is associated with long-term risk of death, institutionalization, and dementia, independent of important confounders (Witlox et al., 2010). It is generally known that a peripheral infection is a common cause of delirium; however, the pathogenesis is still poorly understood. Evidence from animal and human studies suggests that microglial cells play a crucial role (Lemstra et al., 2007; Cunningham, 2013).

Microglial cells, the tissue macrophages of the central nervous system (CNS), are considered to be the main cell type of the innate immune system in the CNS. In a normal situation, microglia are regulated tightly in a balanced environment of pro- and anti-inflammatory mediators produced by surrounding healthy brain tissue. Threats to the homeostasis of the CNS, for example a peripheral infection, can provoke a rapid change in phenotype of the microglia from surveilling cells into active cells producing inflammatory mediators. In high concentrations, these inflammatory mediators are potentially neurotoxic and activate other surveilling microglia. Normally, microglial activation is regulated by inhibitory mechanisms so this vicious circle becomes interrupted. Examples of known inhibitory mechanisms on microglial cells are the cholinergic anti-inflammatory pathway (Shytle et al., 2004), fractalkine (CX3CL1) and its receptor (CX3CR1) (Cardona et al., 2006), cluster of differentiation 200 (CD200) and its receptor (CD200R) (Hoek et al., 2000), and cluster of differentiation 47 (CD47) and its receptor signal regulatory protein $\alpha$ (SIRP- $\alpha$ ) (Oldenborg et al., 2001). A possible explanation for the association of delirium with poor outcome is that activated microglia escape their

\footnotetext{
Abbreviations: 7-AAD, 7-amino-actinomycin D; APC, allophycocyanin; $\mathrm{CD} 11 \mathrm{~b}$, cluster of differentiation 11b; CD16, cluster of differentiation 16; CD32, cluster of differentiation 32; CD45, cluster of differentiation 45; cDNA, complementary deoxyribonucleic acid; CFU's, colony-forming units; CI, confidence interval; CNS, central nervous system; CSF, cerebral spinal fluid; DAB, diaminobenzidine; deltaCt: delta cycle threshold; E. coli, Escherichia coli; $\mathrm{EU}$, endotoxin units; GKN-BSA, glucose-potassium-sodium buffer; HMGB1, high-mobility group 1; Iba-1, ionized calcium binding adaptor molecule 1; Ig, immunoglobulin; IL-1 $\beta$, interleukin 1 beta; IL-6, interleukin 6; IL-12, interleukin 12; IVC, individually ventilated cages; LB, Luria-Bertani medium; LPS, lipopolysaccharide (LPS); MCP-1, monocyte chemotactic protein 1; M-CSF, macrophage colony-stimulating factor; mRNA, messenger ribonucleic acid; NoNo, Non-POU-domain containing octamer binding protein; PBS, phosphate buffered saline; PE, phycoerythrin; PerCP, peridinin-chlorophyll-protein; qPCR, quantitative polymerase chain reaction; RNA, ribonucleic acid; TGF- $\beta$, transforming growth factor beta; TNF- $\alpha$, tumor necrosis factor alpha.
}

inhibitory mechanisms, fueling chronic uncontrolled neuroinflammation (Witlox et al., 2010). To test this hypothesis there is a need for a clinical relevant animal model.

In a systematic review of the literature we described that, in experimental studies in rodents, peripheral challenge with lipopolysaccharide (LPS) causes a profound immunological response in the brain resulting in microglial activation (Hoogland et al., 2015). However, this LPS model poorly simulates the clinical situation, where inflammation is normally caused by infection with live bacteria and is commonly treated with antibiotics. In literature, studies examining microglial activation after systemic challenge with live bacteria are scarce, but results suggest that live bacteria cause microglial activation that is less profound as compared to that found in the experiments using a challenge with LPS.

The main purpose of this study is to introduce a mouse model where systemic challenge with live bacteria causes a neuro-inflammatory response. Secondly, we want to illustrate the differences in course of neuro-inflammation between systemic challenge with live bacteria and systemic challenge with LPS. We intraperitoneally injected mice with live E. coli or with LPS. Microglial response was measured using immunohistochemical staining with ionized calcium-binding adaptor molecule 1 (Iba-1) antibody (cell number and morphology) and flow cytometry (cell size, $\mathrm{CD} 45$ and $\mathrm{CD} 11 \mathrm{~b}$ expression); and inflammatory response by measuring messenger ribonucleic acid (mRNA) expression of pro- and anti-inflammatory mediators.

\section{MATERIALS AND METHODS}

\section{Animals}

In total, 138 specific pathogen-free 8-week old male wild type C57BL/6J mice were purchased from Charles River (Maastricht, The Netherlands) and maintained at the animal care facility of the Academic Medical Centre (University of Amsterdam). Mice were housed in groups of 3 to 6 , in individually ventilated cages (IVC), for at least 2 weeks before testing. Ambient temperature was 19$24^{\circ} \mathrm{C}$ with $40-70 \%$ humidity. According to national guidelines, food and water were available ad libitum and a 12:12 h lightdark cycle was retained. All experiments were approved by the Institutional Animal Care and Use Committee of the Academic Medical Center (Amsterdam, the Netherlands).

\section{Bacteria}

E. coli (K1:O18) was grown to an optical density at $600 \mathrm{~nm}$ in Luria-Bertani medium (LB) at $37^{\circ} \mathrm{C}$ corresponding to midlog phase. E. coli were harvested by centrifugation at 3,000 rpm for 
$10 \mathrm{~min}$ and washed twice with pyrogen-free sterile isotonic saline. Bacteria were diluted to a final concentration of $1 \times 10^{4}$ colonyforming units (CFU's) in $200 \mu \mathrm{l}$ pyrogen-free sterile isotonic saline. Serial 10 -fold dilutions of the final bacterial inoculum were plated on blood agar plates and incubated overnight at $37^{\circ} \mathrm{C}$ to verify the amount of viable bacteria injected.

\section{Experimental Procedures}

In experiments investigating the effects of a bacterial infection, mice ( $n=15$ per time point) were given a single intraperitoneal injection of $1 \times 10^{4} \mathrm{CFU}$ in $200 \mu \mathrm{l}$ pyrogen-free sterile isotonic saline (range $\left.1.0 \times 10^{4}-1.8 \times 10^{4} \mathrm{CFU}\right)$. Control mice $(n=6$ per time point) received $200 \mu \mathrm{l}$ of pyrogen-free sterile isotonic saline via intraperitoneal injection. Inoculations were performed in different experiments and mice were sacrificed at 12, 20,48, and $72 \mathrm{~h}$ after inoculation. As the administered dose of $E$. coli is lethal after 20-22 h, we treated the mice that were sacrificed 48 and $72 \mathrm{~h}$ after inoculation with ceftriaxone. Ceftriaxone (Fresenius Kabi, Den Bosch, the Netherlands) was intraperitoneally injected 12 and $24 \mathrm{~h}$ after $E$. coli injection in a dose of $20 \mathrm{mg} / \mathrm{kg}$. For these time points ( 48 and $72 \mathrm{~h}$ ) an extra control group ( $n=6$ per time point) with ceftriaxone treatment was added. Mice that were sacrificed $12 \mathrm{~h}$ after inoculation were only used for analysis of sickness behavior, weight loss and bacterial outgrowth to explore the $E$. coli infected mouse model.

In experiments investigating the effects of LPS injections, mice ( $n=15$ per time point) received LPS derived from $E$. coli (O111:B4 strain, Ultrapure, Invivogen) at a dose of $5 \mathrm{mg} / \mathrm{kg}$ via intraperitoneal injection. This dose and strain was chosen for its reliable induction of microglia activation and reproducible cytokine response in the brain (Hoogland et al., 2015). Control mice ( $n=6$ per time point) received $200 \mu$ l of pyrogen-free sterile isotonic saline via intraperitoneal injection. Mice were sacrificed at 3 and $48 \mathrm{~h}$ after LPS or pyrogen-free sterile isotonic saline injection.

Inoculation for all experiments was done at the same time of day, around 8.00 a.m. For the LPS model we chose the most commonly used dose and strain for LPS in literature; $5 \mathrm{mg} / \mathrm{kg}$ of E. coli O111:B4. For that reason we chose to use E. coli for the live bacteria model, but due to technical limitations we used a different strain, K1:O18.

Time points for collecting tissues differ between LPS injected mice $(t=3 \mathrm{~h}$ and $t=48 \mathrm{~h}$ ) and for $E$. coli injected mice ( $t=20 \mathrm{~h}, t=48 \mathrm{~h}$, and $t=72 \mathrm{~h}$ ). Hence, direct comparison of results between LPS injected mice with those injected with E. coli is not possible. These time points were chosen based on available literature, which shows neuro-inflammatory response to LPS injection after approximately 3 to $6 \mathrm{~h}$, and moderate neuro-inflammatory response after injection of live bacteria after roughly 1 to 7 days (Hoogland et al., 2015). Therefore, we chose different time points to examine early response for the two groups. Additionally, based on this literature, we expected more profound neuro-inflammatory response after injection of live bacteria to occur even later and included the $72 \mathrm{~h}$ time point for this group.

The weight of all mice was measured before inoculation, administration of ceftriaxone, or saline and mice termination.
Weight loss was considered a quantitative measurement for the degree of sickness. Additionally sickness behavior was monitored during experiments. The design of the different experiments is illustrated in Appendix Table 1.

Mice were anesthetized by intraperitoneal injection of ketamine (190 mg/kg, Eurovet Animal Health, Bladel, the Netherlands) and medetomidine $(0.3 \mathrm{mg} / \mathrm{kg}$, Pfizer Animal Health, Capelle aan den IJssel, the Netherlands). Body weight was assessed, after which cardiac puncture for blood collection followed. Blood was collected in sterile tubes containing EDTA and stored on ice. The abdomen was opened and the vena cava was severed, subsequently cerebral spinal fluid (CSF) was collected by puncture of the cisterna magna, collected in sterile tubes and stored on ice. Thereafter the thorax was opened and perfusion of organs with sterile phosphate buffered saline (PBS) was performed via the left cardiac ventricle (approximately $20 \mathrm{ml} \mathrm{PBS}$ in $5 \mathrm{~min}$ ). Next the spleen, the median lobe of the liver and the brain were harvested. The right hemisphere was suspended in $10 \%$ buffered formalin and embedded in paraffin for histopathology. The left hemisphere was either suspended in $5 \mathrm{ml}$ of Hibernate-A medium (Invitrogen) and stored by $4^{\circ} \mathrm{C}$ ( $n=5$ experimental group $/ n=3$ control group) or taken up in $20 \%$ weight per volume sterile saline $(n=10$ experimental group $/ n=3$ control group) as well as the median lobe of the liver and the spleen. The organs suspended in sterile saline were put on ice and were disrupted with a tissue homogenizer. Directly after homogenizing the organs, $50 \mu \mathrm{l}$ of the tissue homogenate was suspended in $350 \mu \mathrm{l}$ RA1 lysis buffer (Kit content of NucleoSpin ${ }^{\circledR}$ RNAII, Macherey-Nagel) and stored at $-80^{\circ} \mathrm{C}$ for mRNA isolation. CSF was diluted 1:100 in sterile saline because of the low collected volumes. Serial 10-fold dilutions of blood, CSF, liver, and spleen homogenates were plated on blood agar plates and bacteria were allowed to grow overnight at $37^{\circ} \mathrm{C}$.

\section{Isolating Microglia for Flow Cytometry}

After overnight storage in Hybernate-A medium at $4^{\circ} \mathrm{C}$, left hemispheres (approximately weighing $250 \mathrm{mg}$ ) were meshed through a $70 \mu \mathrm{m}$ cell strainer (Nylon, BD Falcon) in a glucosepotassium-sodium buffer [GKN-BSA; $8 \mathrm{~g} / \mathrm{l} \mathrm{NaCl}, 0.4 \mathrm{~g} / \mathrm{l} \mathrm{KCl}$, $1.77 \mathrm{~g} / \mathrm{l} \mathrm{Na} 2 \mathrm{HPO}_{4} .2 \mathrm{H}_{2} \mathrm{O}, 0.69 \mathrm{~g} / \mathrm{l} \mathrm{NaH}{ }_{2} \mathrm{PO}_{4} . \mathrm{H}_{2} \mathrm{O}, 2 \mathrm{~g} / \mathrm{l} \mathrm{D}-(1)-$ glucose, $\mathrm{pH}$ 7.4] with $0.3 \%$ bovine serum albumin (Roche) and collected in $50 \mathrm{ml}$ tubes. After centrifuging (1400 rpm, $7 \mathrm{~min}, 4^{\circ} \mathrm{C}$ ), cell pellets were suspended in $1 \mathrm{ml}$ enzyme buffer $\left(4 \mathrm{~g} / \mathrm{l} \mathrm{MgCl}_{2}, 2.55 \mathrm{~g} / \mathrm{l} \mathrm{CaCl}_{2}, 3.73 \mathrm{~g} / \mathrm{l} \mathrm{KCl}\right.$, and $8.95 \mathrm{~g} / \mathrm{l} \mathrm{NaCl}, \mathrm{pH}$ 6-7), followed by enzymatic digestion in collagenase type I (370 units, Worthington) and DNase I (10 $\mathrm{mg} / \mathrm{ml}$, Roche) for $45 \mathrm{~min}$, at $37^{\circ} \mathrm{C}$, while shaking. After enzymatic dissociation, cells were washed with GKNBSA buffer and incubated for $2 \mathrm{~min}$ on ice in $2 \mathrm{ml}$ cold erythrocyte lysis buffer $\left(8.3 \mathrm{~g} / \mathrm{l} \mathrm{NH}_{4} \mathrm{Cl}, 1 \mathrm{~g} / \mathrm{KHCO}_{3}\right.$, and $0.03 \mathrm{~g} / \mathrm{l}$ EDTA, pH 7.4). Subsequently, cells were washed and resuspended in $20 \mathrm{ml}$ Percoll (GE healthcare) of $\rho=1.03$, then underlaid with $10 \mathrm{ml}$ Percoll of $\rho=1.095$ and overlaid with $5 \mathrm{ml}$ of GKN-BSA buffer. The tubes were centrifuged for $35 \mathrm{~min}$ at $1200 \times \mathrm{g}$ at $20^{\circ} \mathrm{C}$, with slow acceleration and no break. The myelin layer on the top of the $\rho=1.03$ phase 
were discarded and cells were collected from the interface between $\rho=1.095$ and $\rho=1.03$ Percoll. Next cells was washed and counted with a Coulter counter (Beckman Coulter, Z2). Approximately $1 \times 10^{5}$ cells from every sample were transferred into separate polystyrene coated round bottomed $5 \mathrm{ml}$ tubes (BD Falcon). Depending on cell numbers, a portion of every sample was put in a pool tube, which subsequently was divided over 5 tubes for a blanc sample and single stainings, every tube contained approximately $1 \times$ $10^{5}$ cells.

Cells were stained in a total volume of $200 \mu \mathrm{l}$ using antibodies with the following specificities: rat anti-mouse CD11b (immunoglobulin (Ig)G2b $\kappa$, clone M1/70, labeled with phycoerythrin (PE), 1:200, BD Pharmigen, rat anti-mouse CD45 [IgG2b $\kappa$, clone 30-F11, labeled with allophycocyanin (APC), 1:500, eBioscience]. To block aspecific binding normal mouse serum (1:10) and anti-mouse CD16/CD32 (Alias Fc $\gamma$ III/II receptor, IgG2b $\kappa$, clone 2.4G2, 1:100, BD Pharmigen) was added. Cells were incubated with antibodies for $30 \mathrm{~min}$ on ice in polystyrene coated round bottomed $5 \mathrm{ml}$ tubes. About $10 \mathrm{~min}$ prior to fixation, $2.5 \mu \mathrm{l}$ of 7 -amino-actinomycin D (7-AAD, labeled with peridinin-chlorophyll-protein (PerCP), 1:80 concentration, BD Pharmigen) was added per sample. After staining, cells were washed and fixated in $2 \%$ paraformaldehyde for $10 \mathrm{~min}$ on ice. Cells were washed and resuspended in $200 \mu \mathrm{l}$ GKN-BSA buffer. Flow cytometric analysis was performed on a FACSCalibur machine (BD) and data were analyzed using FlowJo software version 7.6.1.

\section{Immunohistochemistry}

Paraffin-embedded brain tissue was sectioned at a thickness of $5 \mu \mathrm{m}$ in a coronal plane from the olfactory bulb to the beginning of the cerebellum. Starting from $1400 \mu \mathrm{m}$, sections were selected at intervals of $500 \mu \mathrm{m}$ throughout the whole brain and mounted on slides (12 sections per mouse). After removal of paraffin in xylene and rehydration in a graded series of alcohols $(100,100,95 \%)$, sections were incubated for $20 \mathrm{~min}$ in $0.3 \%$ hydrogen peroxidase $\left(\mathrm{H}_{2} \mathrm{O}_{2}\right)$ diluted in methanol to block the endogenous peroxidase activity. Antigen retrieval was performed by incubation for $10 \mathrm{~min}$ at $120^{\circ} \mathrm{C}$ in $0.01 \mathrm{M}$ citrate buffer $(\mathrm{pH} 6.0$ ). Slides were washed with PBS and incubated with the primary antibody; Iba-1 (rabbit polyclonal, 1:2000, Wako Pure Chemical Industries). Slides were incubated with Iba-1 for $1 \mathrm{~h}$ at room temperature. Thereafter, sections were washed with PBS and were incubated for $30 \mathrm{~min}$ at room temperature with the ready-for-use PowerVision peroxidise system (HRP, Immunologic). As a chromogen 3.3'diaminobenzidine (DAB, Sigma) was used and sections were counterstained with hematoxylin (1:10 diluted, incubated for $3 \mathrm{~min})$.

Luxol fast blue-Periodic acid-Schiff-hematoxylin staining was used to discriminate between white and gray matter and was compared to microglial staining to select different brain regions for analysis. In the end slides were dehydrated and coverslipped with Pertex.

\section{Quantification of Immunohistochemistry Images}

After staining all slides were scanned with a D. Sight fluo (A. Menarini, Florence, Italy) at 20x magnification. Two square millimeter of each digital image of cortex, hippocampus, thalamus, and caudate nucleus/putamen was selected. Microglial cell bodies were manually counted and morphologically reviewed by one observer, who was blinded for all mice characteristics (ICMH).

\section{Definition of Microglial Activation}

Microglial cells were defined as activated based on the following criteria: (1) microglia showed an activated morphology based on immunohistochemical staining; (2) there was a significant increase in microglial cell number, quantified with immunohistochemical staining, (3) there was a significant increase in size of microglia, quantified with flow cytometry (increase in forward scatter compared to the control group); and (4) there was a significant increase in expression of a microglial marker, quantified with flow cytometry (expression of CD45 and/or CD11b). When 3 or 4 of the stated parameters were positive, microglial cells were defined as activated. When 1 or 2 parameters were positive, microglial cells were defined as moderately activated and when all parameters were negative, microglial cells were defined as inactive.

\section{RNA Extraction and Real Time qPCR}

Total ribonucleic acid (RNA) was extracted from murine brain and spleen homogenates using the nucleospin II extraction kit (Macharey-Nagel GmbH, Duren, Germany). The concentration of the RNA was measured using Nanodrop Spectophotometer (Nanodrop Technologies, USA) and the purity was assessed by the ratio of absorbance at 260 and $280 \mathrm{~nm}$. RNA purity was within range of 2.0-2.1. Complementary deoxyribonucleic acid (cDNA) was synthesized from equal amounts of RNA using Iscript ${ }^{\text {tm }}$ according to the manufacturer's protocol (Biorad Laboratories, Hercules, USA). Gene-specific analysis by real-time quantitative polymerase chain reaction (qPCR) was performed using an iCycler MyiQTM system with Bio-Rad $\mathrm{iQ}^{\mathrm{tm}}$ SYBRGreenSupermix (Biorad Laboratories, Hercules, USA). Expression levels were normalized to reference gene Non-POU-domain containing octamer binding protein (NoNo). Primer sequences are depicted in Appendix Table 2. A negative control without the Reverse Transcriptase was also used. Data were analyzed using the Bio-Rad MyiQ Optical system Software version 1.0 and expression data were calculated using the delta cycle threshold (deltaCt) method.

\section{Statistical Analysis}

Continuous variables were tested with Mann-Whitney $U$ tests or Student $t$-tests depending on sample size and distribution of the data. The assumption of normality was tested with the Kolmogrov-Smirnov test. Since time points, type of infection and treatment were variable, we only compared an infected group with its control group and did 
not directly compare the different time points or infected groups with one another. Statistical significance was set to $P \leq 0.05$. Because of the exploratory nature of this study, correction for multiple comparisons was not applied. For visual presentation of quantitative results, GraphPad Prism was used (GraphPad Software, version 6.07, La Jolla, CA, USA).

\section{RESULTS}

\section{Description of Mouse Models}

To delineate differences of microglial activation after systemic stimulation with live E. coli and LPS, mice were either intraperitoneally injected with E. coli $\left(1 \times 10^{4}\right.$ CFUs $)$ and sacrificed at $12,20,48$, and $72 \mathrm{~h}$ or with LPS $(5 \mathrm{mg} / \mathrm{kg})$ and sacrificed after 3 and $48 \mathrm{~h}$; E. coli infected mice were treated with intraperitoneal injection with ceftriaxone (48 and $72 \mathrm{~h}$ time points). At 20 and $24 \mathrm{~h}$, all mice showed signs of sickness; which consisted of reduction of movement and grooming. Behavior returned to normal at $48 \mathrm{~h}$ although the mean weight loss was 5\% (95\% confidence interval [CI] 3$7 \%)$ in the E. coli group and 7\% ([CI] 5-9\%) in the LPSgroup (Appendix Figure 1). CFUs in E. coli infected mice at the $12 \mathrm{~h}$ time point were elevated for blood, spleen, and liver, but not for (CSF). At $20 \mathrm{~h}$ after E.coli injection CFUs were elevated for blood, spleen, liver, and CSF. CFUs decreased after ceftriaxone treatment; CSF cultures of all E. coli mice were negative at 48 and $72 \mathrm{~h}$ after infection (Appendix Figure 2).

\section{Microglial Activation}

In $E$. coli infected mice, microglia activation parameters were negative at the $20 \mathrm{~h}$ time point post-stimulation. At $48 \mathrm{~h}$, immunohistochemistry showed increased cell number in cortex only (mean 140 cells $/ 2 \mathrm{~mm}^{2}$ [95\% CI 117-163 cells/2 $\mathrm{mm}^{2}$ ] vs. 103 cells $/ 2 \mathrm{~mm}^{2}$ [CI $88-118$ cells $/ 2 \mathrm{~mm}^{2}$ ] controls; $p=0.005$ ), but no differences in hippocampus (mean 117 cells $/ 2 \mathrm{~mm}^{2}$ [CI 112-122] vs. 109 cells $/ 2 \mathrm{~mm}^{2}$ [CI 97-122]; $p=0.24$ ), thalamus (mean 85 cells $/ 2 \mathrm{~mm}^{2}$ [CI 82-88] vs. 79 [73-86]; $p=0.10$ ), and caudate nucleus/putamen (mean 117 cells $/ 2 \mathrm{~mm}^{2}$ [CI 103-131] vs. 118 cells $/ 2 \mathrm{~mm}^{2}$ [CI 110-125]; $p=0.94$; Figure 1). There were no morphological changes on immunohistochemistry at the 20 and $48 \mathrm{~h}$ time points (Figure 2). At $48 \mathrm{~h}$, flow cytometry showed increased CD45 expression $(p=0.04)$, but similar cell size $(p=0.15)$ and CD11b expression $(p=0.24)$, as compared to isolated microglia cells from our control mice (Figure 3). However, at $72 \mathrm{~h}$, immunohistochemistry showed increased cell number in cortex (mean 147 cells $/ 2 \mathrm{~mm}^{2}$ [CI 135-159] vs. 103 cells $/ 2 \mathrm{~mm}^{2}$ [CI 88-118]; $p=0.0002$ ), hippocampus (mean 133 cells $/ 2 \mathrm{~mm}^{2}$ [CI 124-142] vs. 109 cells $/ 2 \mathrm{~mm}^{2}$ [CI 97-122]; $p=0.003$ ), and thalamus (mean 107 cells $/ 2 \mathrm{~mm}^{2}$ [CI 96-117] vs. 79 cells $/ 2 \mathrm{~mm}^{2}$ [CI 73-86]; $p=0.0001$ ), but not in the caudate nucleus/putamen (mean 123 cells $/ 2 \mathrm{~mm}^{2}$ [CI 107-140] vs. 118 [CI 110-125]; $p=0.33$; Figure 1), and moderate morphological activation (Figure 2). Consistent with this finding, flow cytometry at $72 \mathrm{~h}$ showed increased cell size $(p=0.03)$ and CD45 expression $(p=0.03)$, without changes in CD11b expression (Figure 3).

In LPS injected mice, microglia activation parameters were negative at the $3 \mathrm{~h}$ time point post-stimulation. However, at $48 \mathrm{~h}$, immunohistochemistry showed increased cell number in cortex (mean 134 cells $/ 2 \mathrm{~mm}^{2}$ [CI 121-147] vs. 108 cells $/ 2 \mathrm{~mm}^{2}$ [CI 99-116] controls; $p=0.002$ ), hippocampus (mean 141 cells $/ 2$ $\mathrm{mm}^{2}$ [CI 120-163] vs. 106 cells $/ 2 \mathrm{~mm}^{2}$ [CI 99-114]; $p=0.0003$ ), thalamus (mean 96 cells $/ 2 \mathrm{~mm}^{2}$ [CI 76-116] vs. 77 cells $/ 2$ $\mathrm{mm}^{2}$ [CI 72-83]; $\left.p=0.007\right)$, and caudate nucleus/putamen (mean 153 cells $/ 2 \mathrm{~mm}^{2}$ [CI 138-167] vs. 114 cells $/ 2 \mathrm{~mm}^{2}$ [CI 109-119]; $p<0.0001$; Figure 1). Additionally, microglial cells showed morphological activation (Figure 2) and flow cytometry of isolated microglial cells showed increased cell size $(p=0.02)$, and expression of CD45 $(p=0.04)$ and CD11b $(p=0.04)$ at 48 h (Figure 3).

\section{Inflammatory Mediators}

We investigated inflammatory response in brain and spleen homogenate by measuring mRNA expression of proinflammatory mediators tumor necrosis factor alpha (TNF- $\alpha$ ), interleukin 1 beta (IL-1 $\beta$ ), interleukin 6 (IL-6), interleukin (IL12) and high-mobility group 1 (HMGB1), immune regulators monocyte chemotactic protein 1 (MCP-1), macrophage colonystimulating factor (M-CSF), and anti-inflammatory mediator transforming growth factor beta (TGF- $\beta$ ) (Figure 4).

In $E$. coli infected mice, mRNA expression of TNF- $\alpha$, IL$1 \beta, \mathrm{HMGB} 1$, and M-CSF in brain homogenate was increased at the $20 \mathrm{~h}$ time point as compared to controls. At 48 and $72 \mathrm{~h}$, all expression levels were similar between $E$. coli infected and control groups. In spleen, mRNA expression of IL-1 $\beta$, IL- 6 , IL-12, HMBG1, MCP-1, and TGF- $\beta$ was significantly increased $20 \mathrm{~h}$ post-infection, while expression of M-CSF was significantly decreased. At $48 \mathrm{~h}, \mathrm{mRNA}$ expression of all expression levels turned to that of the controls, except for IL-1 $\beta$ (significant increase), while at $72 \mathrm{~h}$ expression of HMGB1 was significantly increased and M-CSF was significantly decreased.

In LPS injected mice, brain mRNA expression levels of TNF- $\alpha$, IL- $1 \beta$, IL-6, MCP-1, and M-CSF in brain homogenates were elevated at the $3 \mathrm{~h}$ time point as compared to controls. At $48 \mathrm{~h}$, expression of TNF- $\alpha$, IL- $1 \beta$, and MCP- 1 remained elevated to some extent, while other brain expression levels returned to that of controls. In spleen homogenate, the systemic compartment, mRNA expression of IL-1 $\beta$, IL-6, IL-12 was significantly increased at the $3 \mathrm{~h}$ time point, while expression of HMGB1 and TGF- $\beta$ was significantly decreased. At 48 h, mRNA expression was significantly decreased for IL-1 $\beta$, IL-6, and IL-12 as compared to the controls and HMGB1 expression remained relatively low.

\section{Effect of Ceftriaxone}

Because a lethal dose of $E$. coli was used, mice that were sacrificed 48 and $72 \mathrm{~h}$ after inoculation were treated with ceftriaxone. To monitor the effect of ceftriaxone we included two extra control groups. Ceftriaxone or pyrogenfree sterile isotonic saline was intraperitoneally injected 12 and $24 \mathrm{~h}$ after pyrogen-free sterile isotonic saline injection. 


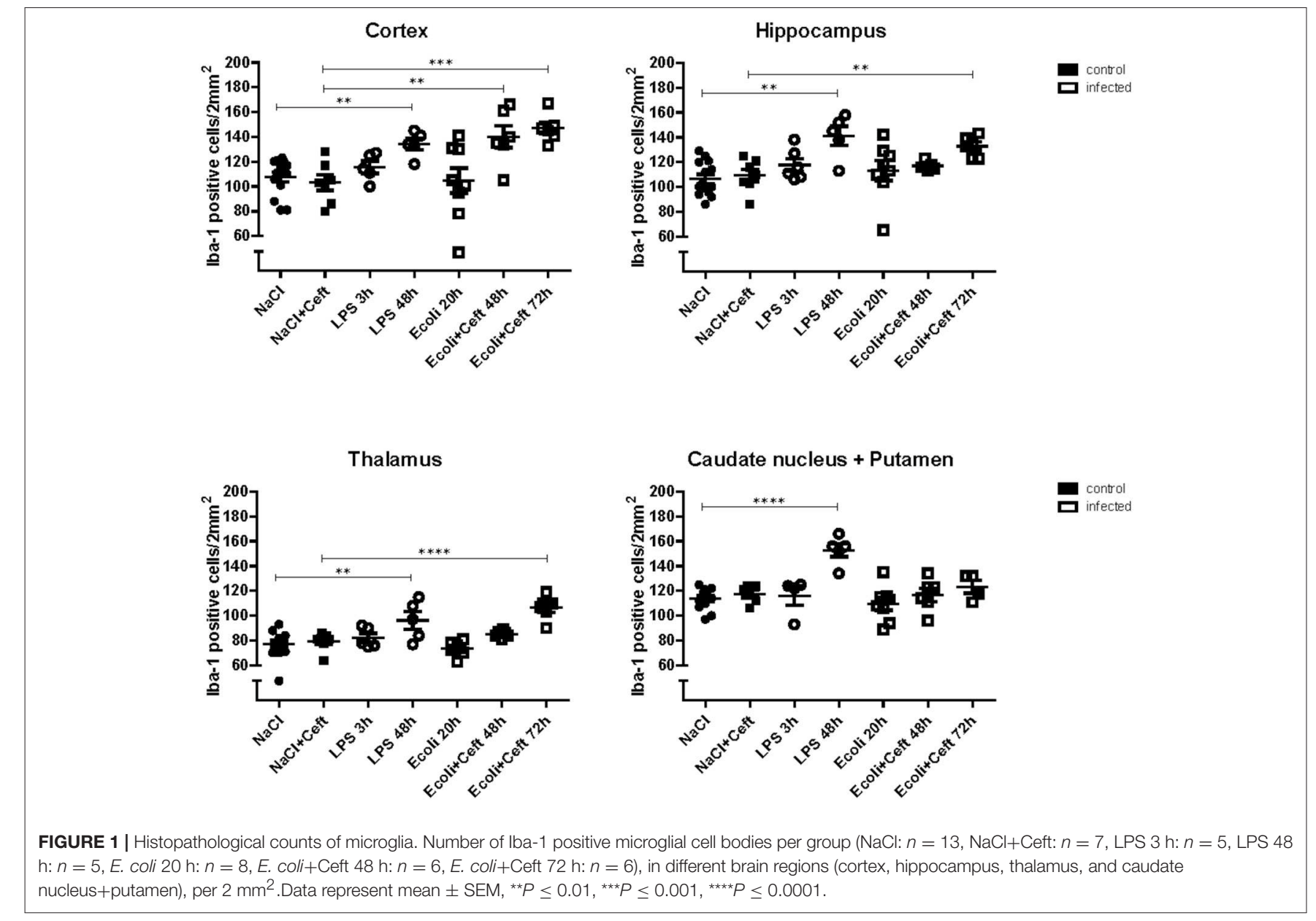

Immunohistochemistry, flow cytometry, and mRNA expression of pro-inflammatory mediators did not differ between these control groups (respectively Figure 1; Appendix Figure 3; and Figure 4).

\section{DISCUSSION}

In this study we introduced a model where systemic challenge with live $E$. coli induces microglial activation 3 days after inoculation, but this activation did not result in production of pro-inflammatory cytokines in the brain. We found more vigorous microglial activation after a single systemic challenge of LPS, with an increase of pro-inflammatory mediators in the brain 2 days after inoculation.

These observed differences in microglial activation and inflammatory response in the brain is in line with previously reported findings (Hoogland et al., 2015), where we suggested distinct differences in microglial activation between systemic stimulation with (supranatural doses) LPS and live or heat-killed bacteria, although heterogeneity among the included studies precluded a firm conclusion. Exact comparison of the dose of
LPS $(5 \mathrm{mg} / \mathrm{kg})$ with the dose of E. coli $\left(1 \times 10^{4} \mathrm{CFU}\right)$ used in our experiments is very difficult. However, according to a rough approximation (where $5 \times 10^{6}$ endotoxin units $(\mathrm{EU}) / \mathrm{ml}$ corresponds to $5 \mathrm{mg} / \mathrm{kg}$ and $1 \mathrm{EU}$ is generated by $1 \times 10^{5} \mathrm{CFU}$ 's) about $1.25 \times 10^{11} \mathrm{CFU}$ are required to yield such an amount of LPS, suggesting that the suspension $E$. coli we used contained about $1 \times 10^{7}$ less CFU's than the LPS suspension. In only one previous study, by Puntener et al. live bacteria were used to systemically infect adult mice and the effects on microglial cells were examined (Puntener et al., 2012). Many studies included in the systematic review used systemic LPS and reported significant microglial activation (Hoogland et al., 2015), whereas the study where mice were inoculated with $1 \times 10^{6}$ CFU's Salmonella typhimurium SL3261 only found moderate microglial activation 7 days after inoculation, showing increased expression of CD11b and CD68 cells in the thalamus (Puntener et al., 2012). With regard to inflammatory response in brain tissue, studies using LPS showed increased pro-inflammatory mediators (such as TNF- $\alpha$, IL-1 $\beta$, and IL-6) in the brain, whereas in the study using live bacteria, brain levels of IL- $1 \beta$ were not increased at the time of moderate microglial activation.

Compared to the study by Puntener et al. (2012), where moderate microglial activation was found 7 days after 

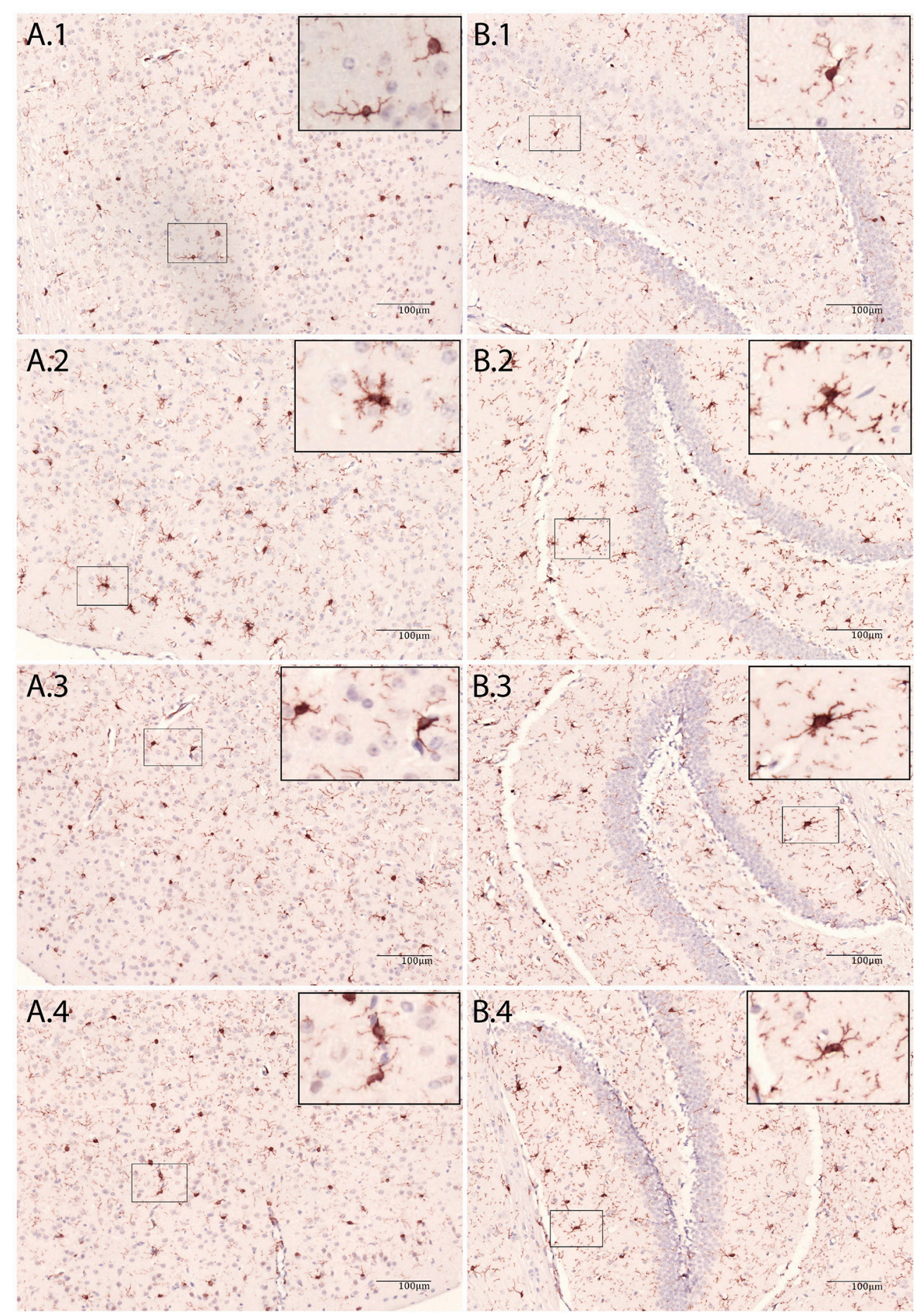

FIGURE 2 | Immunohistochemic staining of brain tissue with Iba-1 antibody. (A) Cortex, (B) Hippocampus, 1: NaCl, 2: LPS 48 h, 3: E.coli + Ceftriaxone 48 h and 4: E.coli + Ceftriaxone $72 \mathrm{~h}$.

inoculation, we report more profound microglial activation occurring relatively early (3 days) after systemic infection challenge. The differences between studies may well be explained by different disease severity between disease models. Our E. coli mouse model would be fatal if the mice were not treated with ceftriaxone. However, comparable to Puntener et al. (2012), there were no quantifiable differences in pro- or anti-inflammatory mediators between infected and control groups in brain homogenate when microglial activation was present. We propose three possible explanations. 


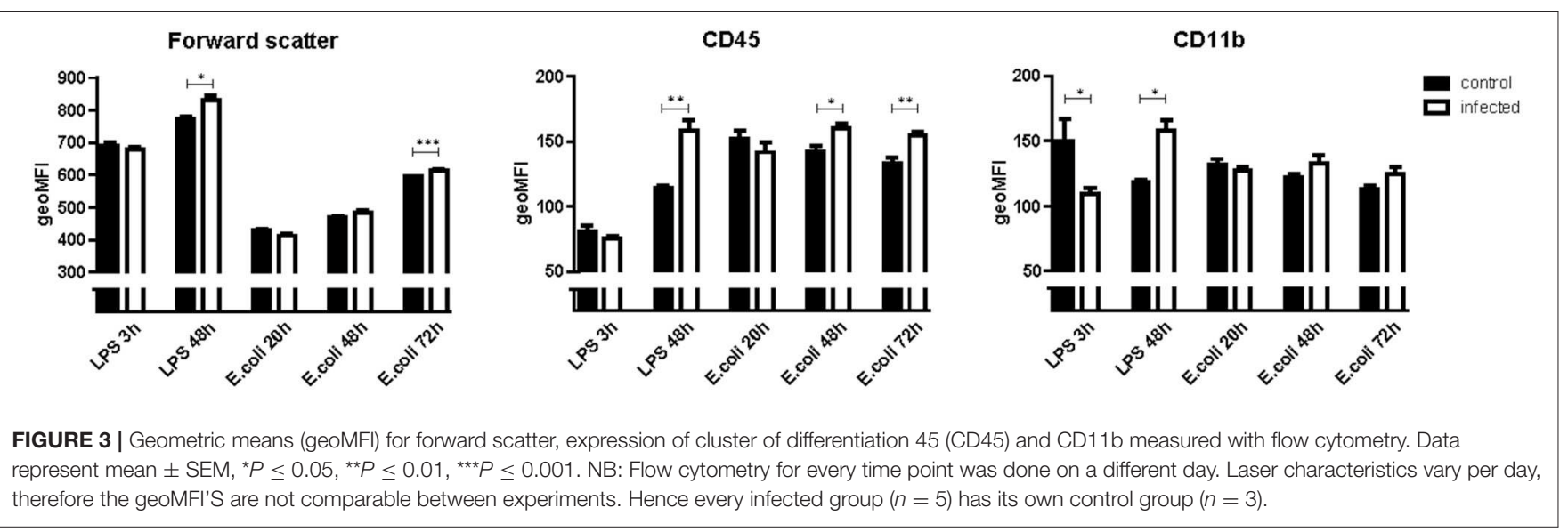

First, it could be a detection problem. The deltaCt's of the measured inflammatory mediators in brain homogenate are low, preventing the detection of small differences between control and infected groups. Second, the inflammatory response may be region specific. At $48 \mathrm{~h}$ after E. coli inoculation, we observed microglial activation in cortex but not in hippocampus, thalamus and caudate nucleus/putamen. Finally, the defined microglial activation at later time points might not be real activation but priming of microglial cells. Like activated microglia, primed microglial cells are increased in cell size, increase the expression of activation markers on their cell surface, and proliferate. However, primed microglial cells are morphologically more ramified than activated microglial cells and do not produce inflammatory mediators (Perry and Holmes, 2014).

Conversely, in LPS injected mice, brain mRNA expression levels of TNF- $\alpha$, IL-1 $\beta$, IL-6, MCP-1, and M-CSF in brain homogenates were elevated at the $3 \mathrm{~h}$ time point as compared to controls, while all microglia activation parameters were negative, questioning where these cytokines come from if they are not induced by activated microglial cells. Qin et al. observed an elevation of TNF- $\alpha$ mRNA and protein levels in brain only $30 \mathrm{~min}$ after a single systemic LPS challenge (5 mg/kg), with a peak at $1 \mathrm{~h}$ (Qin et al., 2007). Their findings suggest that systemic LPS acts by inducing systemic TNF- $\alpha$ synthesis, which is then transported across the blood brain barrier via TNF- $\alpha$ receptors and activates microglial cells to induce TNF- $\alpha$ and other cytokines (Qin et al., 2007). When looking at our data, in the LPS $3 \mathrm{~h}$ group, almost all cytokines that are upregulated in brain (TNF- $\alpha$, IL-1 $\beta$, IL$6, \mathrm{MCP}-1$, and M-CSF) are also upregulated in spleen (IL$1 \beta$, IL-6, and M-CSF), which partly confirms the finding of Qin et al. that peripheral cytokines are possibly transported over the blood brain barrier after systemic challenge with LPS (Qin et al., 2007).

HMGB1, a protein previously known only as a nuclear transcription factor, has been implicated as a mediator of delayed endotoxin lethality in systemic inflammation (Andersson and Tracey, 2003). In our study mRNA expression of HMGB1 was down regulated after LPS stimulation and up regulated after infection with $E$. coli, in spleen homogenate in more extent than in brain, which implicates a different course of inflammatory response. Differences of HMGB1 expression in the two models may also be explained by difference in time points. However, HMGB1 has also been suggested to mediate neuro-inflammatory priming in the aged brain and HMGB1 antagonism prevented prolonged infection-induced neuro-inflammatory and sickness responses in aged rats treated with live E. coli (Fonken et al., 2016).

\section{Limitations}

To monitor the effect of ceftriaxone as a third variable we included an extra control group where ceftriaxone was added. No differences in neuro-inflammatory response was found compared to the control group where saline was added. To examine the effect of ceftriaxone during inflammation, ceftriaxone has to be added to the LPS groups. Our main goal was to introduce a mouse model where systemic challenge with live bacteria causes a neuroinflammatory response, therefore to fully examine the effect of ceftriaxone was beyond the scope of our study.

The protocol for isolating and staining microglial cells for flow cytometry was based on a human protocol (Melief et al., 2012). In this human protocol, intermediate CD45 expression distinguished microglial cells from infiltrating macrophages, which had high CD45 expression. In our mouse samples there was only one cell population of CD45 positive cells. When this population was compared to a blood sample which was stained with CD45, the expression of CD45 positive cells of the brain samples was much lower. Furthermore, before brain tissue was collected, the brain was perfused with PBS via the left ventricle of the heart, preventing interference of blood cells. Therefore, we concluded that this one cell population of CD45 positive cells were in fact all microglial cells.

The next step in research is to implement this E. coli model in different experiments. We used young adult mice, while sepsis associated delirium and its late complications, is most common in older patients (Inouye, 2006). It is well-known that aging has its effect on the adaptive immune system. The innate immune system remains intact whereas the adaptive 


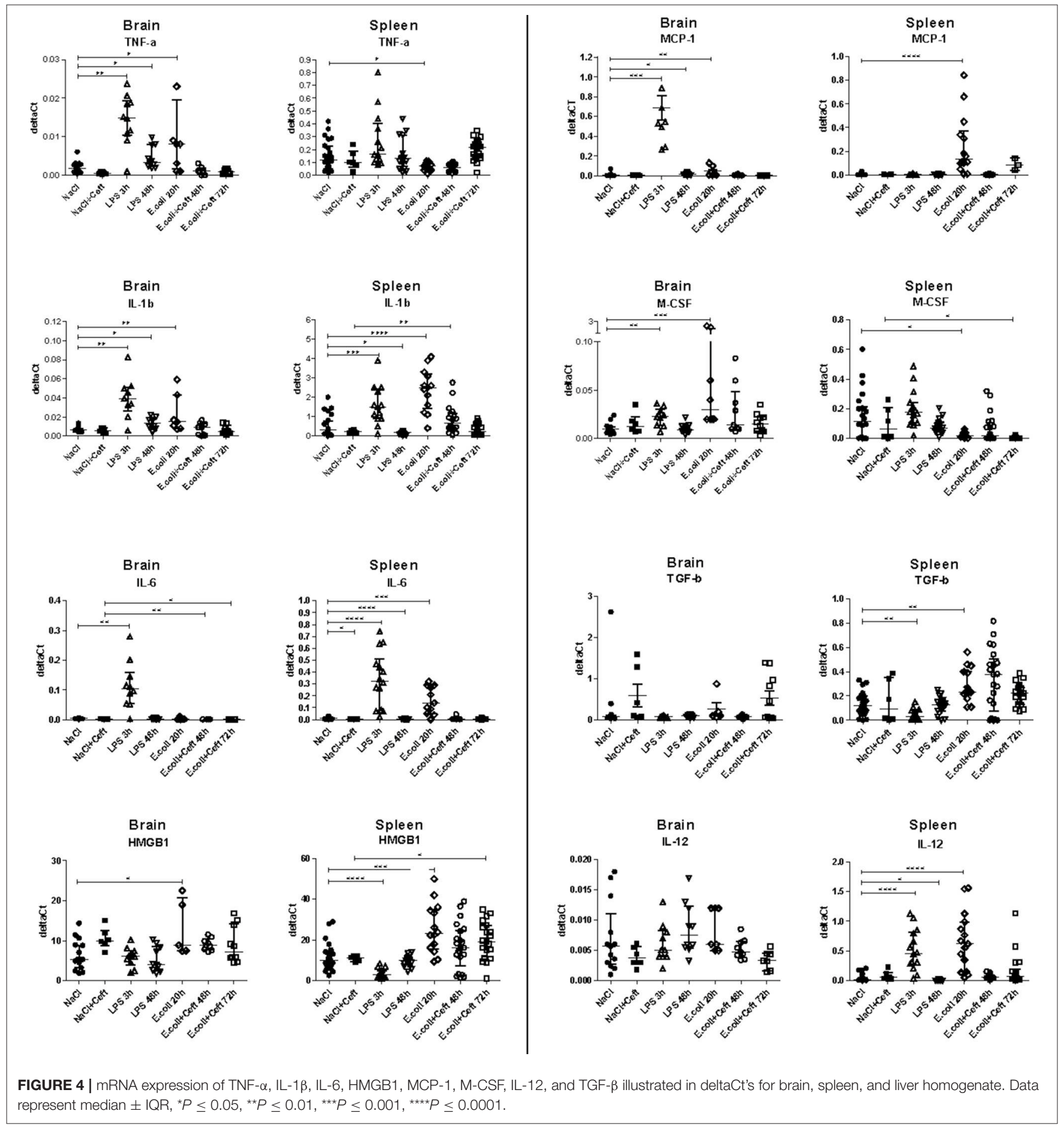

immune system reduces its activity, resulting in a chronic low-grade pro-inflammatory state, also known as inflammaging (Cevenini et al., 2013). This suggests an important role of aging in the process of connecting systemic inflammation, microglial activation, and sepsis associated delirium. The introduction of this model is a first step; although an extreme phenotype of microglia activation was not found, this finding is in line with our hypothesis (Witlox et al., 2010).
Future experiments should evaluate differences in microglial response after infection with live bacteria in old and young mice.

\section{CONCLUSION}

We conclude that it is possible to cause microglia activation with an abdominal infection model with live E. coli. We observed 
distinct differences in microglial activation between systemic stimulation with live E. coli and (supranatural doses of) LPS, with earlier, more profound microglial activation and inflammatory response in the brain after systemic LPS. Because the animal model, where live bacteria are used to cause an infection and this infection is subsequently treated with antibiotics, simulates the clinical situation closely, it might be more suited to examine the pathogenesis of infection associated delirium than the LPS model.

\section{AVAILABILITY OF DATA AND MATERIALS}

The datasets used and/or analyzed during the current study are available from the corresponding author on reasonable request.

\section{AUTHOR CONTRIBUTIONS}

The work presented was carried out in collaboration between all authors. Experimental procedures were carried out by ICMH, $\mathrm{DW}$, and MV with technical assistance of JH-W. The protocol

\section{REFERENCES}

Andersson, U., and Tracey, K. J. (2003). HMGB1 in sepsis. Scand. J. Infect. Dis. 35, 577-584. doi: 10.1080/00365540310016286

Cardona, A. E., Pioro, E. P., Sasse, M. E., Kostenko, V., Cardona, S. M., Dijkstra, I. M., et al. (2006). Control of microglial neurotoxicity by the fractalkine receptor. Nat. Neurosci. 9, 917-924. doi: 10.1038/nn1715

Cevenini, E., Monti, D., and Franceschi, C. (2013). Inflamm-ageing. Curr. Opin. Clin. Nutr. Metab. Care 16, 14-20. doi: 10.1097/MCO.0b013e32835ada13

Cunningham, C. (2013). Microglia and neurodegeneration: the role of systemic inflammation. Glia 61, 71-90. doi: 10.1002/glia.22350

Fonken, L. K., Frank, M. G., Kitt, M. M., D’Angelo, H. M., Norden, D. M., Weber, M. D., et al. (2016). The alarmin HMGB1 mediates age-induced neuroinflammatory priming. J. Neurosci. 36, 7946-7956. doi: 10.1523/JNEUROSCI.1161-16.2016

Hoek, R. M., Ruuls, S. R., Murphy, C. A., Wright, G. J., Goddard, R., Zurawski, S. M., et al. (2000). Down-regulation of the macrophage lineage through interaction with OX2 (CD200). Science 290, 1768-1771. doi: $10.1126 /$ science. 290.5497 .1768

Hoogland, I. C., Houbolt, C., van Westerloo, D. J., van Gool, W. A., and van de Beek, D. (2015). Systemic inflammation and microglial activation: systematic review of animal experiments. J. Neuroinflammation 12:114. doi: 10.1186/s12974-015-0332-6

Inouye, S. K. (2006). Delirium in older persons. N. Engl. J. Med. 354, 1157-1165. doi: 10.1056/NEJMra052321

Lemstra, A. W., Groen in't Woud, J. C., Hoozemans, J. J., van Haastert, E. S., Rozemuller, A. J., Eikelenboom, P., et al. (2007). Microglia activation in sepsis: a case-control study. J. Neuroinflammation 4:4. doi: 10.1186/1742-2094-4-4

Melief, J., Koning, N., Schuurman, K. G., Van De Garde, M. D., Smolders, J., Hoek, R. M., et al. (2012). Phenotyping primary human microglia: tight regulation of LPS responsiveness. Glia 60, 1506-1517. doi: 10.1002/glia. 22370 for isolated microglia for flow cytometry was provided by JM and IH. Flow cytometric analysis was performed by ICMH with assistance of JM. Histopathological assessment of slides was performed by ICMH and J-YE-L. The manuscript was drafted by ICMH and discussed and edited by DvdB. All authors have read and approved the final version of the manuscript.

\section{FUNDING}

This work was supported by ZonMW (WvG, TOP grant \#4000812-98-10017). DvdB is supported by The European Research Council (ERC Starting Grant \#281156) and ZonMW (Vidi grant \#016.116.358).

\section{SUPPLEMENTARY MATERIAL}

The Supplementary Material for this article can be found online at: https://www.frontiersin.org/articles/10.3389/fncel. 2018.00110/full\#supplementary-material

Oldenborg, P. A., Gresham, H. D., and Lindberg, F. P. (2001). CD47signal regulatory protein alpha (SIRPalpha) regulates Fcgamma and complement receptor-mediated phagocytosis. J. Exp. Med. 193, 855-862. doi: 10.1084/jem.193.7.855

Perry, V. H., and Holmes, C. (2014). Microglial priming in neurodegenerative disease. Nat. Rev. Neurol. 10, 217-224. doi: 10.1038/nrneurol.2014.38

Puntener, U., Booth, S. G., Perry, V. H., and Teeling, J. L. (2012). Long-term impact of systemic bacterial infection on the cerebral vasculature and microglia. J. Neuroinflammation 9:146. doi: 10.1186/1742-2094-9-146

Qin, L., Wu, X., Block, M. L., Liu, Y., Breese, G. R., Hong, J. S., et al. (2007). Systemic LPS causes chronic neuroinflammation and progressive neurodegeneration. Glia 55, 453-462. doi: 10.1002/glia.20467

Shytle, R. D., Mori, T., Townsend, K., Vendrame, M., Sun, N., Zeng, J., et al. (2004). Cholinergic modulation of microglial activation by alpha 7 nicotinic receptors. J. Neurochem. 89, 337-343. doi: 10.1046/j.1471-4159.2004.02347.x

Witlox, J., Eurelings, L. S., de Jonghe, J. F., Kalisvaart, K. J., Eikelenboom, P., and van Gool, W. A. (2010). Delirium in elderly patients and the risk of postdischarge mortality, institutionalization, and dementia: a meta-analysis. JAMA 304, 443-451. doi: 10.1001/jama.2010.1013

Conflict of Interest Statement: The authors declare that the research was conducted in the absence of any commercial or financial relationships that could be construed as a potential conflict of interest.

Copyright (C) 2018 Hoogland, Westhoff, Engelen-Lee, Melief, Valls Serón, HoubenWeerts, Huitinga, van Westerloo, van der Poll, van Gool and van de Beek. This is an open-access article distributed under the terms of the Creative Commons Attribution License (CC BY). The use, distribution or reproduction in other forums is permitted, provided the original author(s) and the copyright owner are credited and that the original publication in this journal is cited, in accordance with accepted academic practice. No use, distribution or reproduction is permitted which does not comply with these terms. 